\title{
Why not start with quarks? Teachers investigate a learning unit on the subatomic structure of matter with 12-year-olds
}

\author{
Gerfried J. Wiener ${ }^{1,2}$, Sascha M. Schmeling ${ }^{1}$ and Martin Hopf ${ }^{2}$ \\ ${ }^{1}$ CERN, European Organization for Nuclear Research, Genève 23, Switzerland \\ 2 Austrian Educational Competence Centre Physics, University of Vienna, Austria \\ For correspondence: jeff.wiener@cern.ch
}

\begin{abstract}
This paper describes the second in a series of studies exploring the acceptance of the subatomic structure of matter by 12-year-olds. The studies focus on a novel learning unit introducing an atomic model from electrons down to quarks, which is aimed to be used at an early stage in the physics curriculum. Three features are fundamental to the unit's design: conveying the central role of models in physics, focusing on linguistic accuracy, and the use of novel typographic illustrations. An initial study saw the iterative redesign and retesting of the unit through 20 one-on-one interviews with grade- 6 students. Findings indicated broad acceptance of most of the unit's key ideas, hinting that the unit's final version is plausible for 12-year-olds. Subsequently, the research was focused on the perspective of teachers to gain insight into their evaluation of the unit's adequacy and didactic feasibility. Therefore, the current follow-up study was designed to introduce the proposed unit to grade- 6 students. This time, instead of education researchers, 13 teachers conducted a set of 17 one-on-one interviews. The teachers had been introduced to the learning unit and the research method during a professional development programme. Our analysis showed that the unit's key ideas were broadly accepted by all the students, who adequately used them for problem-solving during the one-on-one interviews. Overall, the documented results validate our findings from the initial study and indicate that the learning unit is adequate and well-suited for a broad evaluation in the classroom.
\end{abstract}

Keywords: Elementary particle physics, Learning unit, Design-based research, Probing acceptance

\section{Introduction}

The particulate nature of matter is considered to be a fundamental topic in science, and in particular in science education (Snir et al., 2003; Boz an Boz, 2008; Treagust et al., 2010; Vikström, 2014). However, studies of students' conceptions about the particulate nature of matter have repeatedly shown that middle and high school students have significant difficulties in establishing an adequate understanding of a particle model. Documented findings show that, in addition to conceptions based on everyday experience, students can develop misconceptions about the particulate nature of matter due to disadvantageous learning materials and interpretations potentially derived from these (de Posada, 1999; Ferk et al., 2003). This is often accompanied by erroneous illustrations in textbooks and over-drawn animations (Andersson, 1990; Adbo and Taber, 2009). Students' conceptions of matter are dominated by a continuum perspective, and the confrontation with a particle model frequently leads to a mixing and overlapping of continuum and discontinuum conceptions, whereby students try to integrate the novel particle model into the framework of the existing continuum model (Pfundt, 1981; Andersson, 19990; Renström et al., 1990; de Vos and Verdonk, 1996; Snir et al., 2003). Furthermore, when introducing a particle model, an automatic transfer of macroscopic aspects into the world of particles occurs, with students thinking of particles with faces and specific colours (Andersson, 1990; Renström et al., 1990; Boz, 2006; Ozmen, 2011; Özalp and Kahveci, 2015). Persistent misconceptions also include the ignoring of the permanent motion of particles and the negation of the existence of 
empty space (Novick and Nussbaum, 1981; Andersson, 1990; Renström et al., 1990; Harrison and Treagust, 1996).

Middle and high school students' documented difficulties with learning about particle models have prompted extensive theoretical and empirical work on how properly to introduce the particle model in the classroom (Talanquer, 2009). To contribute to the large body of research on the introduction of particle models, we have developed a learning unit on the subatomic structure of matter, which aims to introduce an atomic model from electrons down to quarks at an early stage in the physics curriculum (Wiener et al., 2015). The unit's design process was approached from a constructivist viewpoint by taking into account students' pre-existing cognitive structures (Duit, 1996; Duit and Treagust, 2003). The rationale of the teaching and learning material thus developed is to enable students to construct knowledge about the subatomic structure without prior physics knowledge.

The unit was developed within the framework of design-based research (Design-Based Research Collective, 2003) through a scheme of iterative retesting and redesign phases by using the technique of probing acceptance (Jung, 1992). This research method relies on the presentation and discussion of information during one-on-one interviews, with defined interview phases aiming to investigate learning processes. In total, we conducted 20 one-on-one interviews with grade- 6 students during the development phase of the unit. We chose 12-year-olds because such students, having been exposed to very little physics education, can be considered to be novices, especially with respect to particle physics. The first testing phase with four students gave insight into the feasibility of the study and the unit's adequacy. As a result, the content of the unit was slightly revised and modified. The new version was then used for a set of eight one-on-one interviews with different students, which prompted an extensive redesign process. Finally, the revised unit was presented to another group of 12-year-olds through a set of eight one-on-one interviews, which led to the final version of the unit (Wiener et al., 2015).

This final version of the unit resulted in a description of the subatomic structure of matter, from which we prepared two different documents: one for students, and one to be used by teachers. The student document is intended to act as a stand-alone version of the unit, which can be used as learning material by grade- 6 students. We then developed a set of documentation for teachers, which, in addition to the student document, contains an annotated version of the learning unit with highlighted key ideas and detailed explanations of their respective uses. The aim of the teacher document is to guide teachers when introducing subatomic particles into the classroom. As a next step, to evaluate the adequacy and didactic feasibility of the learning unit, we focused our research on the perspective of teachers. Therefore, the presented follow-up study was designed to have experienced physics teachers conduct another set of one-on-one interviews with grade- 6 students. The teachers took part in a professional development programme, in which they were instructed about the content, aims, and goals of the learning unit and trained to use the technique of probing within the one-on-one interview. Given that these interviews and their outcomes are strongly tied to the content of the learning unit itself, we first give a brief overview about its main concepts, before explaining the rationale and methods of the follow-up study in detail.

The final version of the learning unit is based on ten key ideas, which are fundamental to the introduction of the subatomic structure of matter (Table I). These elementary steps were reconstructed to adequately introduce the topic to 12-year-olds at the beginning of their physics education. Peer validation was sought from education researchers and experts in particle physics, who found that these reconstructed elementary steps are suitable for such an introduction. As shown in Table I, the set of key ideas can be divided in two sections: key ideas I \& II as general ideas, and key ideas III-X as particle model ideas, which illustrate the specific model of particle physics examined in the learning unit. 
Table I. Key ideas of the learning unit on the subatomic structure of matter.

\begin{tabular}{cl}
\hline$\#$ & \multicolumn{1}{c}{ Key ideas } \\
\hline I & Matter is everything that can be touched, practically or theoretically. \\
II & Reality is described through models. For example the model of particle physics. \\
& \\
III & In the model of particle physics, there are atoms, which may combine to form compounds. \\
IV & In this model, atoms are divided into two areas: the nucleus-space and the orbital-space. \\
V & In the nucleus-space, protons and neutrons are located. \\
VI & Protons and neutrons are particle systems, which are made of quarks. \\
VII & Quarks are indivisible. In this model, these are called elementary particles. \\
VIII & In the orbital-space, it is possible to find electrons. \\
IX & Electrons are indivisible. In this model, these are called elementary particles. \\
X & In this model, apart from particles, there is only empty space.
\end{tabular}

This model presents electrons and quarks as elementary particles, while stating that protons and neutrons are particle systems, which are made of quarks. In contrast to elementary particles the notion of empty space is introduced. Here, the model purposely omits the introduction of vacuum fluctuations, as documented students' conceptions show that the introduction of the concept of empty space is already a challenging task in the classroom. Hence, to avoid unnecessary confusion, this specific key idea $(X)$ was formulated solely to introduce empty space as the counterpart to elementary particles. We consider this a suitable reconstruction for 12-year-olds, which can be expanded in a meaningful way at a later stage in the curriculum.

Furthermore, the model in question uses a simplified depiction of hadrons as combinations of only quarks. The rationale of this approach is to start with elementary particles and then - in the unit's second chapter - introduce fundamental interactions and their associated bosons. However, since the second chapter is beyond the scope of the study presented, we intentionally excluded every notion of fundamental interactions within the model examined in the learning unit. Nonetheless, we want to highlight the intended possibility of further building upon the learning unit to combine both elementary particles and fundamental interactions as the basics of the Standard Model of particle physics.

In addition to the ten key ideas, over the course of the initial study, three features turned out to be essential to the unit's design: conveying the central role of models in physics, focusing on linguistic accuracy, and the use of novel typographic illustrations. While these three features were originally introduced only to ensure comprehensiveness and coherence, they also seemed to have a major impact on avoiding triggering any of the documented misconceptions about the particulate nature of matter (Wiener et al., 2015). Below is a brief overview of the three features, highlighting their main objectives and how they are used in the final version of the learning unit.

Model-building has been considered to be a key process in the development of scientific knowledge, and it is argued that thinking in and with models is an essential component of appropriate science knowledge (Hestenes, 1987; Ornek, 2008; Chittleborough and Treagust, 2009; Justi, 2009). In the 1990s, both the National Science Education Standards and National Council of Teachers of Mathematics Standards as well as Benchmarks for Science Literacy recommended 'models and modelling' as the unifying theme for science and mathematics education in the US, which has been reflected in the development of a modelling instruction programme (Wells et al., 1995; Hestenes, 2003; Jackson et al., 2008). However, when looking at common practice, education research shows that neither modelling nor thinking in models are sufficiently developed by either students (Danusso et al., 2010; Grünkorn et al., 2011; Khan, 2011; Krell et al., 2012; Krell et al., 2015) or teachers (Gilbert, 2004; Koponen, 2007; Topcu, 2013). Bearing this in mind and addressing models as "effective pedagogical tools" for 
teaching scientific literacy (Halloun, 2007: 653), the proposed unit focuses strongly on conveying the central role of modelling in physics by emphasising its model aspect. We consider the chapter of elementary particles to be prototypical for a model-based approach to physics teaching and the phrase "With this model, we describe ..." thus plays a big role in the unit. Furthermore, as the learning unit is intended to be used at the beginning of the physics curriculum, the 'model of particle physics' is introduced to serve both as a prominent example of a commonly-used model in physics, and as the overarching theme of the unit. Consequently, the notion of the model aspect is frequently repeated and emphasised in the final version of the unit's key ideas.

The second prominent aspect of the proposed unit is linguistic accuracy. The unit's design relies on careful definitions of key words and key phrases (Table II) to distinguish everyday language from a language of science, a distinction thought to be beneficial to learners (Brown and Ryoo, 2008; Rincke, 2011). For instance, when talking about particles, the proposed unit distinguishes between 'particles' and 'particle systems', which is reflected in key ideas VI, VII \& IX. This means that only elementary particles, such as leptons and quarks, are denoted as particles. In contrast, hadrons count as particle systems, which are made of particles. However, particle systems can still be described as particle-like objects with particle-like properties. When introducing the atomic model, instead of 'the nucleus', the unit refers to 'the nucleus-space'. Doing so avoids the potential misconception that one can 'touch the nucleus', while unambiguously reinforcing the location aspect of the nucleus-space. The same idea is applied when the 'orbital-space' is introduced, emphasising the probability aspect of particles while avoiding any anachronistic descriptions of 'circular orbits' as a possible source of misconceptions (Karsten et al., 2011).

Table II. Overview of key words central to the unit and how they are used in phrasings.

\begin{tabular}{cl}
\hline Key word & \multicolumn{1}{c}{ Key phrasing } \\
\hline Description & Reality is described through models, e.g. the model of particle physics. \\
Particle & In the model of particle physics, electrons and quarks are elementary particles. \\
Particle System & Protons and neutrons are particle systems, which are made of quarks. \\
Nucleus-space & Protons and neutrons are located in the nucleus-space. \\
Orbital-space & In the orbital-space, it is possible to find electrons. \\
\hline
\end{tabular}

Conveying the probability aspect is also supported by the use of certain key phrasing. For instance, instead of introducing electrons that 'are' in the orbital-space, the unit's key idea VIII emphasises that 'it is possible to find' electrons in the orbital-space, and thus avoids any notion of movement of electrons. While still a challenging step, this key idea serves as a basic concept and adequate reconstruction of probability distributions for 12-year-olds. Furthermore, it can be meaningfully linked to at a later stage in the physics curriculum, as it introduces the notion of orbitals early on. Another prominent example of linguistic accuracy is used for the unit's key idea I, which introduces the key word 'matter' through the defining property of 'touching'. Here, we discovered that it is necessary to specify that matter can be touched practically (for example, ordinary matter such as a table, the wall, or clothes) and theoretically (for example, the moon or "a lion, because I think I can touch it, but I would never do it." [Quote from one of the grade-6 students taking part in the initial study; all quotes translated by the authors from the original German])

In addition to linguistic accuracy, the unit relies on carefully constructed illustrations, since education research shows that visual representations are essential for communicating ideas in the science classroom (Carney and Levin, 2002; Cook, 2006). However, due to the inconceivable size ratios in the field of particle physics, it is challenging to produce even adequate illustrations, let alone realistic ones. Therefore, to avoid triggering misconceptions, and bearing in mind the central role of models in physics, we propose a novel typographic approach. Herein, instead of misleading visualisations as spheres, particles are represented by their respective symbol. The same applies to particle systems, 
with their respective symbols enveloping those of their respective constituent elementary particles (Figure 1).

These illustrations were iteratively tested and modified during the initial study. By the end of this process, we hardly encountered any transfer of macroscopic aspects onto the properties of subatomic objects. As the students' evaluations suggest this was mostly due to the revised typographic illustrations, we consider them to be an essential feature of the unit discussed. To further distinguish particles from particle systems, the underlying colour scheme has been thoroughly thought through: the symbols of particle systems are kept in grey, while particles' symbols are drawn in colour. For instance, the symbols of quarks are blue, green, and red. For our research, this serves the sole purpose to identify quarks as particles, but it sets up the notion of colour charge to be used when introducing fundamental interactions in future additions to the unit.

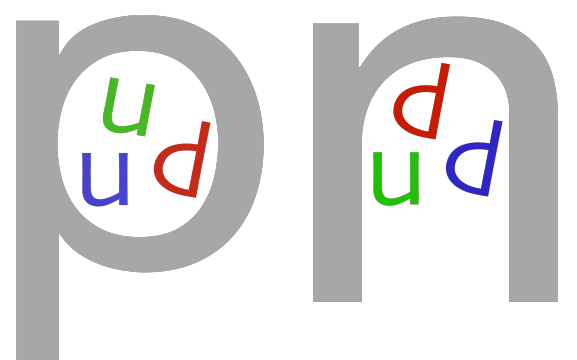

Figure 1. Typographic illustrations of a proton and a neutron.

A typographic approach was also developed to illustrate the atomic model. This visualisation displays the names of both the nucleus-space and the orbital-space, the latter being made to look spherical (Figure 2). This gives the impression of a three-dimensional atomic model while reducing the possible misimpression of orbits or shells. As our unit is designed to be used at the beginning of the physics curriculum, this visualisation of the atomic model aims only to illustrate the distinction between the nucleus-space and the orbital-space introduced through key idea IV. However, it sets up the notion of different orbital shapes within the specific orbital-space, which must be introduced at a later stage in the physics curriculum. Furthermore, the visualisation requires a careful introduction by the teacher to explain its underlying model aspect, as it does not overcome the problem of a realistic size ratio, which can be demonstrated additionally using interactive animations, simulations, and animated movies.

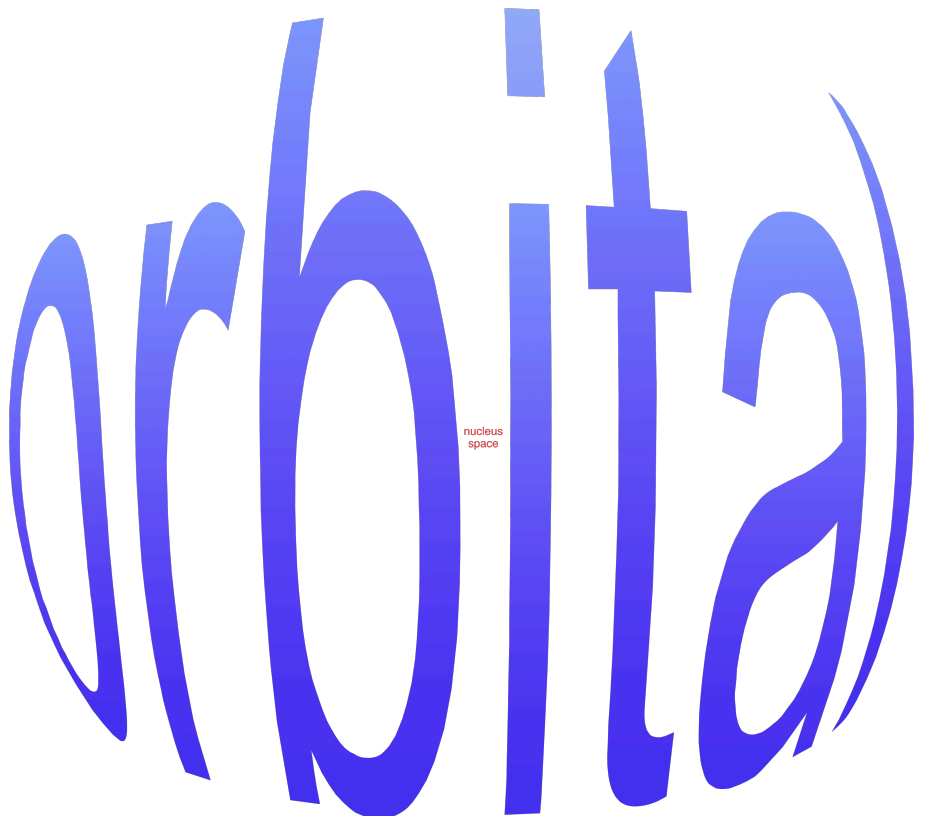

Figure 2. Typographic illustration of the atomic model. 


\section{Research Question}

The aforementioned initial study saw the iterative redesigning and retesting of the proposed learning unit through 20 one-on-one interviews with grade- 6 students. Findings indicated broad acceptance of most key ideas, hinting that the unit's final version can indeed be understood by 12 -year-olds. The most promising outcomes of the initial study are pure typographic illustrations. Not only were these accepted by all grade- 6 students, but they also led to a reduction of known misconceptions. The illustrations turned out to be particularly helpful when it came to the distinction between particles and particle systems. The underlying colour pattern, supported by the careful wording, led to a clear distinction. Overall, the students who took part in the study displayed a greatly improved understanding of elementary particles, but occasionally showed avoidance when considering the role of models in physics (Wiener et al., 2015). However, these initial results only showed that students could make use of the unit's final version and accept its key ideas when it was introduced by the research team. Therefore, as a next step, we focused our research on the perspective of teachers, to gain insight into their evaluation of the unit's adequacy and didactic feasibility. Hence, the present article addresses this topic through the following research question:

\section{How do grade-6 students evaluate and make use of the learning unit on the subatomic structure of matter when it is introduced by experienced teachers as opposed to education researchers?}

To evaluate the research question, a follow-up study was designed to investigate the proposed unit with grade- 6 students. This time, the one-on-one interviews were led by experienced teachers, instead of by education researchers. The rationale of this approach was to compare their results with those of the initial study, to evaluate whether broad acceptance of the unit's key ideas can be achieved by teachers as well. Ultimately, this would demonstrate the unit's applicability and prepare the ground for a broad field study to facilitate its integration in the classroom.

\section{Methods}

Theoretical framework. To investigate the research question, the follow-up study was designed in accordance with our previous study (Wiener et al., 2015). Specifically, the study design was based on the technique of probing acceptance, which was developed by Jung (1992) to investigate learning processes. This research method relies on students' evaluation, paraphrasing, and adaptation of information presented during a one-on-one interview with defined student-centred interview phases. This particular setting is similar to a quasi-experimental one-on-one tutoring session with several tasks to be completed by the student during each interview phase. An advantage of this setting compared to conventional problem-centred interviews when seeking to identify resistances to elements of the information input is the reduction of short-term, ad hoc constructs (Wiesner and Wodzinski, 1996). Thus, we consider the technique of probing acceptance to be well-suited to develop adequate teaching and learning material. Depending on the definition of 'acceptance', however, the name of the research method can be misleading and therefore needs clarification. For the purpose of developing our unit, we focused the research method on evaluating the plausibility of our unit and whether it makes sense to students. Probing acceptance then means identifying elements of the instruction that students accept as useful and meaningful information, and which they can successfully adapt during the one-on-one interview.

Study design. We invited teachers to take part in education research to further evaluate the developed learning unit on the subatomic structure of matter from a teaching point of view. Hence, the study was implemented in a professional development programme for teachers, formed of two parts: a briefing session, and an intervention (Figure 3). The briefing session took place the day before the intervention and lasted about three hours. Its design was based on the assumption that all teachers participating in the study would have basic knowledge of particle physics. For our Austrian and 
German teachers, this turned out to be true, as all of them had received a university-level physics degree. Furthermore, all teachers participating in the study had vast experience in teaching basic concepts of particle physics, such as the subatomic model of matter. Since particle physics is part of both the Austrian and German physics curricula for grade 12, it did not come as a surprise that all teachers also showed considerable understanding of the Standard Model of particle physics during the briefing session. In addition, we noted that all teachers were very interested in learning about alternative instructional strategies regarding particle physics. However, we found that none of the teachers had deep knowledge of students' existing conceptions about particle physics. Hence, instead of updating the teachers' content knowledge, the briefing focused on instructing them about the key ideas of the novel learning unit and on helping them prepare for the intervention. The main idea of the briefing was to highlight the approach of the learning unit, by confronting teachers with documented students' conceptions of the particulate nature of matter. Therefore, a presentation on the concepts of the unit was given, which explained its development, gave an overview of students' documented conceptions of the structure of matter, and highlighted the unit's key ideas. This presentation took one hour and was followed by the introduction of the research method.

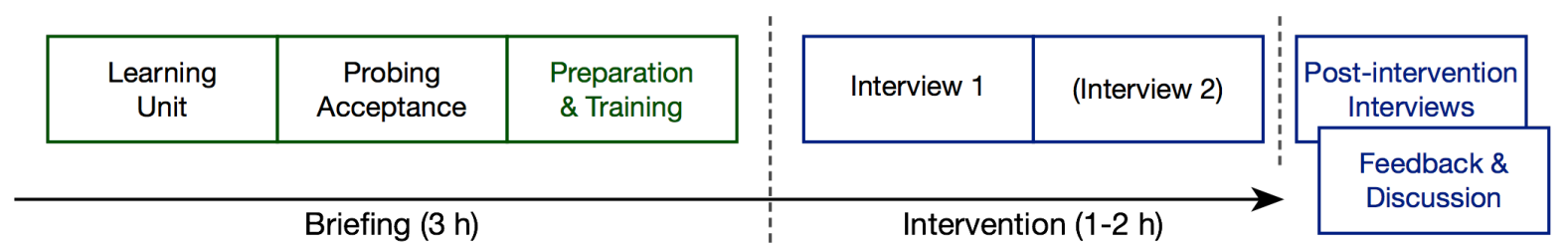

Figure 3. Design of the professional development programme with a briefing session followed by an intervention. During the intervention, each teacher conducted at least one one-on-one interview. Additionally, where time and planning allowed, teachers conducted a second one-on-one interview with a different grade- 6 student immediately after their first interview. The intervention was concluded by post-intervention interviews, which were conducted individually with every teacher. In parallel, a feedback and discussion session enabled the remaining teachers to collectively reflect on their experiences and discuss main outcomes of their one-on-one interview(s).

During this next hour, the technique of probing acceptance was explained in detail by presenting representative examples from our previous study, which were then discussed among the teachers. Additionally, all teachers received their own research manuals, which we developed to enable teachers to conduct the one-on-one interview in accordance with the setting of the study and to ensure comparability among all teachers. It contained a set of anchor phrases to facilitate conducting the interview (Table III), a list of the ten key ideas, and the general timeframe of the interview. The research manual was discussed and worked through with the teachers to summarise the presentation of the technique of probing acceptance.

For the last hour of the briefing, it was the teachers' task to prepare themselves for the intervention, individually and collectively, by trying out the handling of the research manual and practicing specific parts of the one-on-one interviews with their colleagues. This part of the briefing session also included time for the preparation of the information input. The latter was left to the discretion of each teacher, making it possible to analyse how they each adapted elements of the learning unit. However, while all teachers were asked to prepare their own information input based on the unit's key ideas individually, teachers were encouraged to discuss their ideas with colleagues while preparing for their instruction during the intervention. To ensure comparability among the teachers and with the setting of our previous study, a general time constraint of 8-10 minutes was given for the duration of the information input, as well as the requirement for teachers to mention every key idea at least once during their instruction. Aside from these conditions, individual preparation, including optional use of digital visualisation (e.g., PowerPoint ${ }^{\odot}$, Prezi $^{\circ}$ ), was then left to the discretion of each teacher. 
Table III. Examples of anchor phrases in the research manual (translated from the original German).

\begin{tabular}{cl}
\hline Phase & \multicolumn{1}{c}{ Key phrases } \\
\hline Evaluation & - How does this sound to you? \\
& - Was the presented information easy to understand? \\
& - Can you recall any details that you could not understand at all? \\
Paraphrasing & - What is your general impression of this information input? \\
& - Can you tell me again - in your own words - everything you \\
Transfer example & - How would you explain this to a friend? \\
& - How does this example relate to what you just heard? \\
& - Hon you think of another, different way of explaining this? \\
\hline
\end{tabular}

The intervention took place on the day following the briefing session and lasted between one and two hours. Every teacher conducted at least one one-on-one interview with a grade- 6 student. Since the intervention took place at the students' and teachers' own school, during school time, we reserved one full hour for each interview session, which only lasted a maximum of 40 minutes. This planning allowed for a relaxed setting and minimised any potential influences due to time pressure or stress for both the teachers and the students. Where given constraints allowed, teachers were encouraged to conduct a second one-on-one interview with a different student during the second hour of the intervention. The rationale of this approach was to give teachers the opportunity to learn from their experience gained during the first interview and thus enable them to adapt their instructional strategies and research phrases for the second interview. While still limiting the whole Intervention to a feasible duration, this schedule allowed for a more detailed analysis regarding the applicability of the unit discussed. Following the intervention, we conducted semi-structured interviews individually with teachers immediately after their one-on-one interview(s). These post-intervention interviews lasted about 15 minutes and were designed to document the teachers' evaluation of both the learning unit and the novel research experience of conducting the one-on-one interview(s). In parallel, the other teachers were enabled to collectively reflect on their experiences with the preparation and execution of their one-on-one interviews. This feedback and discussion session concluded the whole intervention.

Setting of the one-on-one interview. Mirroring the original setting of the initial study, the one-on-one interviews were designed to comprise four interview phases with a maximum interview duration of 40 minutes (Figure 4). All teachers were guided through their one-on-one interview by the research manual. Key to the manual's design was the list of the ten key ideas, which had to be worked through by the teachers. During each interview phase, every key idea was to be addressed, discussed, and explained by the student, and then ticked off the list. Only once all key ideas had been discussed could the next interview phase begin. The research manual's checklist can be found in the appendix to this article.

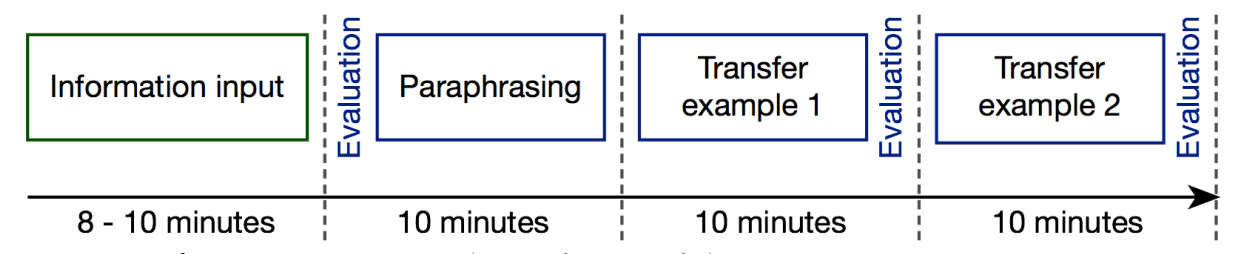

Figure 4. Setting and timeframe of the one-on-one interview.

Each one-on-one interview started with the presentation of the information input, which was individually prepared by each teacher. This was followed by a first evaluation of the student to document immediate feedback on the novel information. For example, they were asked by the 
teacher, "What do you think about this topic?" and, "Was there anything that you could not understand? Or anything that you really liked?". This evaluation also marked the beginning of the second interview phase. The teacher was then prompted by the manual to ask their student to paraphrase the presented information "in their own words". Here, the student was tasked with recalling as much of the initial information input as possible. This paraphrasing concluded the second interview phase.

Next, as a first transfer example, it was the teacher's task to sprinkle some grains of salt across the table and ask the student to apply the new knowledge to this concrete example by solving the problem of whether salt can be identified as matter, and to explain what salt is made of. To conclude the third interview phase, this transfer example was followed by the student's second evaluation of the information input.

For the fourth and final phase of the one-on-one interview, it was the teacher's task to guide the student through the second transfer example. This example set the same challenge as the first transfer example, but instead of using grains of salt the teacher dripped some droplets of water on the table. It was then the student's task to explain whether water qualifies as matter and to further give a description of what it is made of. While both transfer examples focused on the same question, the rationale of this approach was to document the students' reasoning for the two different aggregate states, solid (salt) and liquid (water). For the final task, each student was asked to give a third and final evaluation of the information input, which concluded the fourth interview phase and marked the end point of the one-on-one interview.

Data collection and analysis. The follow-up study took place at one Austrian and four German middle schools (Gymnasium, age group: 10-18 years) with a total of 13 teachers (6 female \& 7 male) and 17 Grade- 6 students (10 female \& 7 male), all of whom volunteered to participate in the study. Furthermore, all teachers received the support from their principals to participate in the study, enabling them to clear their schedules for four consecutive lessons, which allowed for a continuous and harmonic data collection. The group of teachers can be seen as a typical sample of Austrian and German middle school teachers. Every teacher had received an academic degree from a university with physics as their main subject. The individual teaching experience varied from 2 to 32 years and thus represents a diverse segment of the population of teachers. During the briefing session all teachers attributed a serious importance to the topic of particle physics and indicated that they felt comfortable discussing particle physics in the classroom.

All told, 17 one-on-one interviews were carried out in German, the native language of all participants. Nine teachers conducted one interview each. A further four teachers conducted two interviews each. To avoid conflicts of interest, most teachers conducted their one-on-one interview(s) with students who were usually taught by another teacher. All students, as well as their parents, gave their informed consent in written form. The participating students were randomly chosen by the teachers, the only limitation being that they be interested in trying out new teaching material. We view this attitude as necessary for the setting of the one-on-one interviews, which we consider to be feasibility studies, to ensure that the students are motivated and confident to take part in the different tasks during the respective interview phases. One might expect teachers to select only their best students to take part in the study. Therefore, we asked all teachers to characterise their student(s) during the post-intervention interviews. As foreseen, most teachers rated their student(s) to be among the best in the class. However, four teachers explicitly mentioned that, due to timing issues, this was not necessarily the case. Instead, they stated that they were lucky to find students, who would even be interested in taking part in the study. In addition, three of the four teachers, who conducted two interviews each, even mentioned that they purposely tried to select two students of different abilities. The motivation behind this approach was explained for example by one of the teachers as follows: "I 
am always a bit sceptical about education research results, because most of these studies do not really show the real world. So I thought I would invite two students who would clearly talk a lot [laughs], but one of them is way smarter than the other."

Based on our analysis, we believe it is safe to say that the students who participated in this study represent a diverse yet positive sample. However, since the students were mainly self-selected and showed considerable interest towards physics, care should be taken in generalising from our findings. Indeed, we want to add the cautionary note that our results are limited to the setting of our study and especially to the students who participated in it. Each one-on-one interview was videotaped using $\mathrm{GoPro}^{\odot}$ cameras and transcribed word by word. To evaluate the findings, the method of qualitative content analysis (Mayring, 2010) was applied by carrying out a category-based analysis on all transcripts. This rule-based, traceable process is based on categories, which meet the research interest and fulfil the standard of reliability. For the evaluation of the transcripts we used the same three categories as in the initial study. Specifically, criteria were defined for each of the ten key ideas to rate statements as either fully adequate, partially adequate, or not adequate. The criteria were developed and peer-validated with other researchers in science education and explicitly formulated in a coding guide. This guide was then used to analyse and evaluate all transcripts. Thirty representative passages, one for each of the three categories of the ten key ideas, served as accompanying examples (Table IV). The complete coding guide can be found in the appendix to this article.

Table IV. Excerpt from the coding guide with criteria and examples for key idea number one: "Matter is everything that can be touched, practically or theoretically." (A statement was rated as fully adequate if and only if all criteria were met.)

\begin{tabular}{|c|c|c|c|}
\hline & Fully adequate & Partially adequate & Not adequate \\
\hline Criteria & $\begin{array}{l}\text { - Mention of matter } \\
\text { - Explanation of touching } \\
\text { as the defining property } \\
\text { of matter } \\
\text { - Distinction between } \\
\text { touching something } \\
\text { practically and } \\
\text { theoretically }\end{array}$ & $\begin{array}{l}\text { - Mention of matter } \\
\text { - Transformation of } \\
\text { touching as the defining } \\
\text { property into the notion } \\
\text { of the solid state of } \\
\text { matter } \\
\text { - Incomplete distinction } \\
\text { between touching } \\
\text { something practically } \\
\text { and theoretically }\end{array}$ & $\begin{array}{l}\text { - No mention of matter } \\
\text { - No or wrong explanation } \\
\text { of touching as the } \\
\text { defining property of } \\
\text { matter }\end{array}$ \\
\hline Examples & $\begin{array}{l}\text { "Matter is everything. Well, } \\
\text { everything I can touch. Even } \\
\text { the air, because, } \\
\text { theoretically, it is touching } \\
\text { me all the time." }\end{array}$ & $\begin{array}{l}\text { "Matter is all the stuff that } \\
\text { is solid and compact." } \\
\text { "Air and water are not } \\
\text { matter because we cannot } \\
\text { grab them." }\end{array}$ & $\begin{array}{l}\text { "I don't know what matter } \\
\text { is." } \\
\text { "If I touch something it } \\
\text { becomes matter." }\end{array}$ \\
\hline
\end{tabular}

For each interview phase, the transcripts were analysed in accordance with the coding guide. Thus, each student's level of acceptance of the unit's key ideas could be identified for each interview phase separately, resulting in a documentation of the learning processes for the entire interview. The analysis was carried out on all transcripts by two independent researchers. Their inter-coder reliability resulted in a Cohen's Kappa of $\kappa=0.86$, meeting the required standard of values higher than 0.8, which are characterised as an almost perfect agreement (Landis and Koch, 1977). 


\section{Results}

The 17 one-on-one interviews led to very positive results. Our analysis showed that all teachers conducted their research session in accordance with the guidelines provided. Our analysis of the oneon-one interviews showed that the unit's key ideas were broadly accepted by all 12-year-olds and all key ideas were used to solve the problems presented by the transfer examples. Overall, the documented results validate our findings from the initial study (Wiener et al., 2015) and evaluate the learning unit to be adequate and well-suited for use by teachers.

In particular, when looking at the ten key ideas, the qualitative content analysis indicated broad acceptance of all key ideas throughout every interview phase. As all ten key ideas were addressed in each of the three interview phases (paraphrasing, transfer example 1, transfer example 2), each oneon-one interview generated 30 key idea mentions. For the 17 one-on-one interviews this resulted in a total of 510 codes. Aside from the vast majority of fully-adequate statements in accordance with the coding guide (494 out of 510; 96.9\%), we documented only a few partially-adequate statements (16 out of $510 ; 3.1 \%$ ) and no inadequate statement. Most partially adequate statements were given during the paraphrasing at the beginning of the interview but were transformed over time to fully adequate statements during the transfer examples. For instance, at the beginning of the one-on-one interview, key words such as 'nucleus-space' and 'orbital-space' were sometimes neglected by the student, but as the interview progressed, these were frequently used for their explanations. In most cases, all key ideas were accepted from the beginning and turned out to be persistent during the entire interview. Here we give a detailed overview of the evaluation of the ten key ideas, and then present the results from our analysis regarding the three features of the learning unit.

Key idea I, which acts as the starting point of the unit by introducing the key word 'matter' through the defining property of 'touching', was broadly accepted by all students. All teachers used key idea I to start their information input and most of them invited their student to brainstorm about different examples of matter. Here, all students immediately displayed understanding that solid objects are examples of matter, but occasionally a discussion with the teacher was required to transfer this knowledge onto liquids and gases. In these cases, all teachers used Socratic questioning, which always led to understanding by the student, for example as follows: "Ah, I never thought of it this way. But of course, when the wind is flowing through my hair it is touching me. So, yes, air is also matter, because it touches us all the time."

Key idea II, which introduces the key word 'model' by linking it to the distinction made in key idea I that matter can be touched either practically or theoretically, was mainly accepted by all students. Specifically, the fact that the unit introduces the 'model of particle physics' which aims to describe reality seemed to appeal to most of the students, as one student emphasised during the paraphrasing phase: "Well, this model of particle physics, as it is called, is one way of describing what is going on in nature. But scientists still need to figure out whether this is really the best way to explain the world." However, during four interviews we noted partially-adequate statements regarding the model aspect of the unit. All four statements occurred during the paraphrasing phase of the one-on-one interview, and all four of them were rated partially-adequate in accordance with the coding guide due to the absence of the key word 'description', as is the case in the following example: "In this model of particles, well, there are particles which make up atoms, and scientists conduct experiments to find even smaller particles of this model."

Key idea III, which introduces the key word 'atom' to the previously mentioned model of particle physics, seemed to appeal greatly to all students. At some point during the information input, every teacher asked their student whether they know what atoms are. In most cases students claimed that they had already heard of atoms, and five students even mentioned that they associated "something 
very small" or "something really tiny" with atoms. Nonetheless, no student could give an adequate ad hoc explanation of atoms at the beginning of the one-on-one interview. As the interviews progressed, however, we only noted fully-adequate statements of the key idea during every interview phase.

Key idea IV, which features the crucial division of the atomic model into the nucleus-space and the orbital-space, also showed no difficulties for the students. Our analysis revealed that during the 17 one-on-one interviews, all criteria of the key idea were met by all students, who consistently made use of the division of the atomic model. Throughout all phases of the interviews we noted frequent use of the key words 'nucleus-space' and 'orbital-space', and only occasionally did we encounter mentions of "the nucleus" and "the orbital".

Key idea V, which introduces the key words 'proton' and 'neutron' by specifying that protons and neutrons are located in the nucleus-space, turned out to be understandable for all students. During most interviews we only encountered correct statements with respect to the location of protons and neutrons in accordance with the coding guide. However, we also noted a few variations of the key word 'nucleus-space', for example "proton-space" and "atomic-space" (In the original German: AtomBereich instead of Atomkern-Bereich), which resulted in a total of eight partially-adequate ratings of the respective statement.

Key idea VI, which explains that protons and neutrons are made of quarks by introducing the key word 'particle system', was accepted and adequately used by all students. Our analysis revealed frequent use of the key word 'particle system' during all interview phases. Overall, the idea behind the key word 'particle system' seemed to appeal greatly to most of the students. For example, one student explained the connection between quarks, protons, and neutrons in their own words as follows: "So, here in the nucleus-space [points to illustration] we have protons and neutrons. They are shown as ' $p$ ' and ' $n$ '. And they are similar to particles, [ehm] but we describe them as particle systems, because they are made of smaller particles. [Hm] Yes, and these smaller particles have a very funny name, I think it was [ehm] something like [ehm] quark, yes, quarks." In addition to the frequent use of the key word "particle system', our analysis showed that no student displayed the conception that quarks are inside of protons or neutrons. Instead, the key phrasing 'protons and neutrons are made of quarks' was frequently used when discussing the key idea, and no misconceptions concerning the description of protons or neutrons were documented.

Key idea VII, which introduces the key word 'elementary particles' and attributes it to quarks, was similarly well received. Not only did all students evaluate the novel term 'quark' to be funny and interesting but ten students even mentioned the indivisibility of elementary particles to be intriguing. In these cases our analysis showed that all teachers started to ask specific questions about the nature of elementary particles, trying to get more specific statements from their student. For example, consider the following statement made by one student: "Well, I mean, I think it is really interesting that there are particles that are elementary particles. But, I mean, [ehm] ok, this is just this model, [ehm] maybe there are even smaller particles and we just do not know them yet." Furthermore, most students used the key word 'elementary particle' as the intended counterpart to particle systems, as shown by one student who asked the following question during the paraphrasing phase: "Do I understand that correctly, there are only elementary particles and they can form to make particle systems? But if this is the case, there are only elementary particles and these [ehm] protons and neutrons are just groups of those quarks?"

Key idea VIII, which introduces the key word 'electron' by stating that it is possible to find electrons in the orbital-space, proved to be understandable to all students. Our analysis showed that all students used the key word 'orbital-space' for their explanations and the key phrase 'it is possible to find' was used frequently by most of the students. Among all one-on-one interviews we only encountered the following partially-adequate rated statement about the location of electrons within 
the atomic model: "And here, these electrons, they fly around in the orbital-space." Aside from this statement, all other statements focused on the intended probability aspect of electrons, in some cases even merged with the model aspect of the atomic model, as follows: "In the orbital-space, here [points to illustration] this is where we could find electrons. So, we do not know where they are precisely, but according to the model [ehm] they have to be somewhere in this area [points to illustration]. "While the probability aspect of electrons remains a challenging concept, especially with regard to linguistic accuracy of its description, our analysis showed that all grade- 6 students attributed electrons to the orbital-space which resulted in a clear distinction between the orbital-space and the nucleus-space, as intended by the learning unit.

Key idea IX, which attributes the key word 'elementary particle' to electrons in the same way as key idea VII did to quarks, led to similar understanding by the students. This did not come as a surprise, as our analysis showed that 12 out of the 13 teachers combined both key ideas at some point during their information input to summarise the notion of elementary particles. Therefore, we almost only noted fully-adequate statements in accordance with the coding guide. However, we did encounter three cases where the student's explanation was lacking linguistic accuracy and the key word 'elementary particle' was either neglected or even transformed, for example into "elementary particle system". In addition, we noted two cases where the similarity of the first syllable of the key words 'electron' and 'elementary particle' caused confusion, for example as follows: "And these quarks, they are also called electrons. [Hm] No... no... not electrons, these are different particles, [ehm] el-em-entary particles, yes, elementary particles. They are indivisible. Quarks and electrons are indivisible and they are called elementary particles [laughs]." Nonetheless, both statements were still rated as fully-adequate in line with the coding guide.

Key idea X, which introduces the key word 'empty space' as the counterpart to particles, seemed to appeal greatly to most students. All students made use of the key word 'empty space' and showed no difficulties when using it during the different interview phases. In contrast to our previous study, we found that no student compared empty space to air. Overall, we only noted fully-adequate statements of the key idea.

Following the evaluation of the ten key ideas, we focused our analysis on the three features of the unit: conveying the central role of models in physics, focusing on linguistic accuracy, and the use of novel typographic illustrations. Here, we also took into account statements made during the respective evaluation of each interview phase. As all three features are strongly linked to the ten key ideas, we were pleased to find promising results here as well, as discussed below.

Model aspect. All 13 teachers successfully conveyed the model aspect of particle physics throughout their one-on-one interviews. Many grade- 6 students adopted the proposed viewpoint of a model as a current description of nature and made frequent use of the key word 'description' (In the original German: Beschreibung) throughout the sessions. For example, one student explained their take on the theory behind the model-based approach of physics as follows: "This is how we describe things right now. But if we continue to do research, it is possible that we will have to change it again." Even when asked to explain the subatomic structure of salt grains and water droplets during the transfer examples, most 12-year-olds automatically mentioned the model of particle physics and referred to the discussed key ideas.

This was also the case when it came to the conceptions known to be especially difficult, such as the indivisibility of elementary particles and the notion of empty space. During every interview phase, many teachers consistently focused on the fact that on a subatomic scale, everything is made of elementary particles. This was broadly accepted by all students and widely used for their explanations of the subatomic structure of salt and water during the transfer examples. Most of the 
students' descriptions were even merged with key idea number ten, which introduces empty space as the counterpart to elementary particles, as put so elegantly by a student: "Since everything is made of electrons, up-quarks, and down-quarks, this has to be the case here as well. If this [salt] does not consist of these three things, there would be nothing." When asked to evaluate the same fact, another student reacted similarly: "That is absolutely clear to me, because what else would it be made of?" In general, to our surprise, the abstract concept of empty space was fairly well accepted and seemed to appeal to most students, as one student formulated during their final evaluation: "Well, I really liked it, because I did not know anything about it. In particular, [I did not know anything] about this empty space and that there are only a few electrons in the orbital-space. This is really fascinating." However, some students felt puzzled by the indivisibility of elementary particles and the notion of empty space, where their acceptance and evaluation differed. Here, the teachers' focus on the unit's model aspect played a key role, since the grade-6 students' questions were mostly expressed from a model-based perspective, as follows: "It is just, as I said, very hard to imagine. But one can orientate oneself based on the model, which helps a lot."

Linguistic accuracy. In addition to the model aspect of the learning unit we paid particular attention to linguistic accuracy, the unit's second feature. Of specific interest was the teachers' use of key words, such as 'orbital-space' and 'nucleus-space', and how it affected and motivated their respective grade- 6 students' use of them. Our findings show that seven teachers used all key words consistently throughout their sessions, which had a considerable impact on their student's paraphrasing of the information input. These students repeatedly and consistently used key words as originally introduced during their respective information inputs. In contrast, during the sessions of the other six teachers, both the teachers and the students transformed key words or neglected some of them. Salient transformations on both sides included "the orbital" and "the nucleus", which may merely have been used as practical shorthand forms. On the students' side, however, we also documented transformations such as "the nucleus-orbital" and "elementary particle systems", which hint at confusion resulting from the lack of linguistic accuracy in these interviews.

When comparing one-on-one interviews of different degrees of linguistic accuracy, our analysis showed no differences regarding the students' acceptance of the unit's key ideas. However, we found connections between the extent to which key words and phrases were used during the one-on-one interviews and the students' attitude towards the learning unit. In interviews with a high degree of linguistic accuracy, our analysis showed that the evaluation of the unit was focused entirely on the content of the subatomic structure of matter. We found that the students still rated aspects of the unit's key ideas to be abstract, but, having no obstructive linguistic elements to discuss, their overall evaluation of the proposed unit was notably positive.

During interviews with a lack of linguistic clarity, on the other hand, the confusion regarding novel terms had a considerable impact on the students' evaluation. Here, their feedback was hugely directed at the linguistic difficulties and only little notice was given regarding the content of the unit. Their evaluations were less profound than those in the aforementioned interviews and only rarely reached a meta-level at which the content itself was evaluated. Our analysis indicates that, while not showing any impact on the students' acceptance of the unit's key ideas, the degree of linguistic clarity drastically influenced the student's evaluation of the proposed unit. Only when teachers followed the guidelines regarding linguistic accuracy by consistently using the unit's key words and phrases were students able to give their evaluation from a cognizant point of view. This highlights the fact that clear-cut language is indeed needed to offer valuable teaching material.

Typographic illustrations. Twelve teachers delivered their information input through a talk, accompanied by typographic illustrations printed out on paper, while one teacher had even prepared a presentation, which was shown on a laptop. During the respective interview phases, all teachers made frequent use of the illustrations and referred back to them when responding to questions from 
the student. All students evaluated the typographic illustrations to be understandable, and their use proved to be comprehensible and adequate. As in our initial study, we did not encounter any 'everyday' descriptions of particles, and no transfer of macroscopic aspects onto the properties of subatomic objects was documented.

Furthermore, the issue of how to properly illustrate particles and particle systems was addressed by several teachers during their interviews. One teacher, for example, chose to focus on the infamous illustration of a glass of water filled with $\mathrm{H}_{2} \mathrm{O}$ molecules floating around in the water. This illustration, which Andersson (1990) used to describe the impact of erroneous illustrations, was presented to the teachers to justify the use of typographic illustrations. The teacher in question used the illustration at the end of their session as the starting point of the final evaluation. The 12-year-old evaluated it as follows: "Well, somehow this line [water level] up here is also strange, because theoretically everything is made of atoms. So, all the water would have to consist of particles. Actually, the glass... this is probably not so important... but the glass would have to be made of particles as well."

\section{Conclusions}

The explicit motivation for this work was to have instructed teachers introduce the subatomic structure of matter to 12-year-olds by using the key ideas and typographic illustration of our proposed learning unit. The presented findings strongly support the results from our initial study (Wiener et al., 2015). Once again, the learning unit, which introduces the subatomic structure of matter, was broadly accepted by 12-year-olds during the one-on-one interviews. Although the evaluated information inputs were prepared and presented individually by experienced teachers in different ways, all of them achieved comparable results and acceptance of key ideas by the grade- 6 students. This supports our assumption that the presented key ideas (Table I) and typographic illustrations are well-suited and adequate for an evaluation in the classroom. However, there are specific details that need to be addressed.

First, key idea II, which focuses on the model-based description of nature, appealed greatly to all the teachers. Thus, the central role of models in physics received numerous mentions throughout every interview. Our findings suggest that this is mainly due to the extensive emphasis placed on the model aspect throughout the unit's key ideas. This is backed up by feedback from the teachers, who, despite being well-trained and qualified physics teachers, evaluated this constant emphasis to be a helpful reminder. Indeed, during the post-intervention interviews, most teachers mentioned that this was helpful during their one-on-one interview(s), and that they would seek to apply it to their own classroom contexts. We consider this to be a very promising detail of our study, as education research shows that science teachers today have often not been explicitly educated and trained in the theme of models and modelling in science (Gilbert, 2004). In turn, the numerous mentions and explanations were highly appreciated by all students, who consistently displayed an epistemological understanding of the model aspect of physics throughout the interviews. This came as a surprise, as our initial study showed that most students accepted a model only as a physical copy of reality. The model itself was then never seriously questioned, which, according to the pioneering study of Grosslight et al. (1991), who divided students' understanding of the 'nature of model' into three different levels, correlated only with a Level 1 understanding. However, compared to our previous findings, the teachers managed to convey a greatly improved model-based description of nature. All students showed acceptance of the viewpoint that a model is created to test ideas, while still accepting this model's potential for change, which corresponds to a Level 3 understanding.

When trying to trace back the reason for this improvement in understanding, we face limitations in our study. Clearly, the teachers' ongoing emphasis of the central role of models in physics had a huge impact on the one-on-one interviews and how the students perceived and evaluated the presented 
information input. However, the teachers' achievement in doing so does not necessarily relate to the learning unit or the research manual developed here. While we are tempted to do so, we are unable to link the grade- 6 students' improved understanding of model-based thinking to the developed unit alone, as our data do not contain any information about the teachers' experience with model-based teaching. Here, we are lacking the possibility to compare the teachers' performance during the oneon-one interviews to their daily teaching practice. Therefore, while having noted strong hints, for our future research, the question remains as to whether our particle physics unit sufficiently supports a model-based approach to teaching physics.

Second, regarding documented students conceptions about the particulate nature of matter, we hardly encountered any persistent misconceptions at any point during the individual one-on-one interviews. By and large, the indivisibility of elementary particles and the notion of empty space were rated as abstract, which did not come as a surprise, as these conceptions are known to be difficult for students (Novick and Nussbaum, 1981; Andersson, 1990; Renström et al., 1990; Harrison and Treagust, 1996; Boz and Boz, 2008). But, in accordance with our previous findings, we did not document any 'everyday' descriptions of particles or any transfer of macroscopic aspects onto their properties. The students' evaluations suggest this is again mostly due to the typographic illustrations, which subtly underline the unit's model aspect, while preventing any macroscopic attributions onto particles. All students evaluated the typographic illustrations to be understandable, and their use proved to be comprehensible and adequate. We therefore suggest typographic illustrations of particles and particle systems as a suitable solution for a model-based approach of teaching particle physics.

Third, we want to stress the fact that while our results are satisfying, there remain aspects of the learning unit that we believe could be further developed and investigated. When looking at the unit's key ideas IV and VIII, for instance, we see the potential of refining both the notion of electrons and the introduction of the orbital-space. For the purpose of our research, these key ideas served as an adequately reconstructed explanation to be used when introducing the theory of orbitals to 12-yearolds. Our results showed that grade- 6 students could make use of the key ideas in their current form. However, without further clarification of their simplicity and an additional refinement at a later stage in the physics curriculum, these key ideas carry the risk of inducing misconceptions about the nature of atoms. This goes hand in hand with the limitations of the typographic illustration of the atomic model (Figure 2). Its intended use was to distinguish the orbital-space from the nucleus-space. Hence, within the learning unit the orbital-space is introduced in spherical form. However, without the introduction of other possible configurations of the orbital-space, which, for instance, can be elegantly demonstrated via animations and interactive visualisations, this approach will most certainly show shortcomings at a later stage in the physics curriculum. Therefore, we see the potential of further modifications through future implementations of the learning unit with older high school students.

Fourth, the young age of our student sample deserves some comment. As mentioned above, we have chosen 12-year-olds for our studies, as such students, having only had very little physics education, can be considered as novices, especially with respect to particle physics. Thus, for our one-on-one interviews, the minimised pre-existence of instructional misconceptions enabled us to trace back possible documented students' conceptions to the information input discussed. In addition, our results support the hypotheses of Nakhleh \& Samarapungavan (1999) and Johnson \& Papageorgiou (2010), who mention the possibility of introducing particle theory at an earlier, rather than later, stage in the curriculum. The feasibility of such a successful application on the classroom level, however, requires much further research. Ideally, our learning unit will support preparation of a broad field study to shed light on the applicability and usefulness of introducing subatomic particles at the beginning of physics education. 
Last, we want to present the research goal for our future work derived from the study presented above. Our analysis revealed that preparing experienced teachers to successfully conduct one-on-one interviews in accordance with our guidelines also enabled them to observe the learning processes of each of their respective grade- 6 students. During the post-intervention interviews, which were conducted immediately after the one-on-one interview(s) to document the teachers' evaluation of the learning unit, all teachers mentioned this very detail to be interesting and informative. In particular, being able to observe how their information input affected their student's performance during the interview phases appealed greatly to the teachers. As education research shows that theory does not necessarily help teachers apply teaching strategies that work on a daily basis in the classroom (Appleton, 2003; Vikström, 2014), we consider the setting of one-on-one interviews to be very promising for bridging this research-teaching gap. Indeed, Nuthall (2004) argues that this effort requires continuous, detailed data on the experience of individual students. Therefore, future research will concentrate on the development and improvement of the technique of probing acceptance as a form of teacher training with respect to teachers' knowledge about students' conceptions and instructional strategies.

\section{References}

Adbo, K., and Taber, K. S., (2009). Learners' mental models of the particle nature of matter: a study of 16-year-old Swedish science students. International Journal of Science Education, 31(6), 757-786.

Andersson, B., (1990). Pupils' conceptions of matter and its transformations (age 12-16). Studies in Science Education, 18, 53-85.

Appleton, K., (2003). How do beginning primary school teachers cope with science? Toward an understanding of science teaching practice. Research in Science Education, 33, 1-25.

Boz, Y., (2006). Turkish pupils' conceptions of the particulate nature of matter. Journal of Science Education and Technology, 15, 203-213.

Boz, N., and Boz, Y., (2008). A qualitative case study of prospective chemistry teachers' knowledge about instructional strategies: introducing particulate theory. Journal of Science Teacher Education, 19, 135-156.

Brown, B. A., and Ryoo, K., (2008). Teaching science as a language: a "content-first" approach to science teaching. Journal of Research in Science Teaching, 45(5), 529-553.

Carney, R. N., and Levin, J. R., (2002). Pictorial illustrations still improve students' learning from text. Educational Psychology Review, 14, 5-26.

Chittleborough, G. D., and Treagust, D. F., (2009). Why models are advantageous to learning science. educación química, 12-17.

Cook, M. P., (2006). Visual representations in science education: the influence of prior knowledge and cognitive load theory on instructional design principles. Science Education, 90, 1073-1091.

Danusso, L., Testa, I., and Vicentini, M., (2010). Improving prospective teachers' knowledge about scientific models and modelling: design and evaluation of a teacher education intervention. International Journal of Science Education, 32(7), 871-905.

Design-Based Research Collective, (2003). Design-based research: an emerging paradigm for educational inquiry. Educational Researcher, 32, 5-8.

Duit, R., (1996). The constructivist view in science education - what it has to offer and what should not be expected from it. Investigações em Ensino de Ciências, 1, 40-75.

Duit, R., and Treagust, D. F., (2003). Conceptual change: a powerful framework for improving science teaching and learning. International Journal of Science Education, 25(6), 671-688.

Ferk, V., Vrtacnik, M., Blejec, A., and Gril, A., (2003). Students' understanding of molecular structure representations. International Journal of Science Education, 25, 1227-1245.

Gilbert, J., (2004). Models and modelling: routes to more authentic science education. International Journal of Science and Mathematics Education, 2, 115-130.

Grosslight, L., Unger, C., Jay, E., and Smith, C., (1991). Understanding models and their use in science: conceptions of middle and high school students and experts. Journal of Research in Science Teaching, 28, 799-822.

Grünkorn, J., zu Belzen, A. U., and Krüger, D., (2011). Design and test of open-ended tasks to evaluate a theoretical structure of model competence. In A. Yarden \& G. Carvalho (Eds.), Authenticity in biology education. Benefits and challenges (pp. 53-65). Braga: CIEC, Universidade do Minho.

Halloun, I. A., (2007). Mediated modeling in science education. Science \& Education, 16, 653-697.

Harrison, A. G., and Treagust, D. F., (1996). Secondary students' mental models of atoms and molecules: implications for teaching chemistry. Science Education, 80, 509-534.

Hestenes, D., (1987). Toward a modeling theory of physics instruction. American Journal of Physics, 55(5), 440-454.

Hestenes, D., (2003). Oersted medal lecture 2002: reforming the mathematical language of physics. American Journal of Physics, 71(2), 104-121.

Jackson, J., Dukerich, L., and Hestenes, D., (2008). Modeling instruction: an effective model for science education. Science Educator, 17(1), 10-17. 
Johnson, P., and Papageorgiou, G., (2010). Rethinking the introduction of particle theory: a substance-based framework. Journal of Research in Science Teaching, 47(2), 130-150.

Jung, W., (1992). Probing acceptance, a technique for investigating learning difficulties. In R. Duit, F. Goldberg \& H. Niedderer (Eds.), Research in physics learning: Theoretical issues and empirical studies (pp. 278-295). Kiel: IPN.

Justi, R., (2009). Learning how to model in science classroom: key teacher's role in supporting the development of students' modelling skills. educación química, 32-40.

Karsten, F., Koch, T., Kranzinger, F., and Theis, M., (2011). Planeten, Wolken oder schwarze Kisten? Wie können wir Atome in der Schule didaktisch sinnvoll beschreiben? Physik Journal, 10, 39-42.

Khan, S., (2011). What's missing in model-based teaching. Journal of Science Teacher Education, 22, 535-560.

Koponen, I. T., (2007). Models and modelling in physics education: a critical re-analysis of philosophical underpinnings and suggestions for revisions. Science \& Education, 16, 751-773.

Krell, M., zu Belzen, A. U., and Krüger, D., (2012). Students' understanding of the purpose of models in different biological contexts. International Journal of Biology Education, 2(2), 1-34.

Krell, M., Reinisch, B., and Krüger, D., (2015). Analyzing students' understanding of models and modeling referring to the disciplines biology, chemistry, and physics. Research in Science Education, 45, 367-393.

Landis, J. R., and Koch, G. G., (1977). The measurement of observer agreement for categorical data. Biometric, 33, 159-174.

Mayring, P., (2010). Qualitative Inhaltsanalyse. In G. Mey \& K. Mruck (Eds.), Handbuch Qualitative Forschung in der Psychologie (pp. 601-613). Wiesbaden: Springer.

Nakhleh, M. B., and Samarapungavan, A., (1999). Elementary school children's beliefs about matter. Journal of Research in Science Teaching, 36, 777-805.

Novick, S., and Nussbaum, J., (1981). Pupils' understanding of the particulate nature of matter: a cross-age study. Science Education, 65, 187-19.

Nuthall, G., (2004). Relating classroom teaching to student learning: a critical analysis of why research has failed to bridge the theory-practice gap. Harvard Educational Review, 74(3), 273-306.

Ornek, F., (2008). Models in science education: applications of models in learning and teaching science. International Journal of Environmental \& Science Education, 3(2), 35-45.

Özalp, D., and Kahveci, A., (2015). Diagnostic assessment of student misconceptions about the particulate nature of matter from ontological perspective. Chemistry Education Research and Practice, 16, 619-639.

Ozmen, H., (2011). Turkish primary students' conceptions about the particulate nature of matter. International Journal of Environmental \& Science Education, 6, 99-121.

Pfundt, H., (1981). Das Atom - Letztes Teilungsstück oder erster Aufbaustein? Zu den Vorstellungen, die sich Schüler vom Aufbau der Stoffe machen. chimica didactica, 7, 75-94.

de Posada, J. M., (1999). The presentation of metallic bonding in high school science textbooks during three decades: science educational reforms and substantive changes of tendencies. Science Education, 83, 423-447.

Renström, L., Andersson, B., and Marton, F., (1990). Students' conceptions of matter. Journal of Educational Psychology, 82(3), 555569.

Rincke, K., (2011). It's rather like learning a language. Development of talk and conceptual understanding in mechanics lessons. International Journal of Science Education, 11(2), 229-258.

Snir, J., Smith, C. L., and Raz, G., (2003). Linking phenomena with competing underlying models: a software tool for introducing students to the particulate model of matter. Science Education, 87, 794-830.

Talanquer, V., (2009). On cognitive constraints and learning progressions: the case of "structure of matter". International Journal of Science Education, 31(15), 2123-2136.

Topcu, M. S., (2013). Preservice teachers' epistemological beliefs in physics, chemistry, and biology: a mixed study. International Journal of Science and Mathematics Education, 11, 433-458.

Treagust, D. F., Chandrasegaran, A. L., Crowley, J., Yung, B. H. W., Cheong, I. P.-A., and Othman, J., (2010). Evaluating students' understanding of kinetic particle theory concepts relating to the states of matter, changes of state and diffusion: a cross-national study. International Journal of Science and Mathematics Education, 8, 141-164.

Vikström, A., (2014). What makes the difference? Teachers explore what must be taught and what must be learned in order to understand the particulate character of matter. Journal of Science Teacher Education, 25, 709-727.

de Vos, W., and Verdonk, A. H., (1996). The particulate nature of matter in science education and in science. Journal of Research in Science Teaching, 33, 657-664.

Wells, M., Hestenes, D., and Swackhamer, G., (1995). A modeling method for high school physics instruction. American Journal of Physics, 63(7), 606-619.

Wiener, G. J., Schmeling, S. M., and Hopf, M., (2015). Can grade-6 students understand quarks? Probing acceptance of the subatomic structure of matter with 12-year-olds. European Journal of Science and Mathematics Education, 3(4), 313-322.

Wiesner, H., and Wodzinski, R., (1996). Akzeptanzbefragungen als Methode zur Untersuchung von Lernschwierigkeiten und Lernverläufen. Lernen in den Naturwissenschaften, 250-274. 


\section{Appendix}

Coding guide

Table A1. Coding guide with criteria and examples for key idea number one: "Matter is everything that can be touched, practically or theoretically."

\begin{tabular}{|c|c|c|c|}
\hline & Fully adequate & Partially adequate & Not adequate \\
\hline Criteria & $\begin{array}{l}\text { - Mention of matter } \\
\text { - Explanation of touching } \\
\text { as the defining property } \\
\text { of matter } \\
\text { - Distinction between } \\
\text { touching something } \\
\text { practically and } \\
\text { theoretically }\end{array}$ & $\begin{array}{l}\text { - Mention of matter } \\
\text { - Transformation of } \\
\text { touching as the defining } \\
\text { property into the notion } \\
\text { of the solid state of } \\
\text { matter } \\
\text { - Incomplete distinction } \\
\text { between touching } \\
\text { something practically } \\
\text { and theoretically }\end{array}$ & $\begin{array}{l}\text { - No mention of matter } \\
\text { - No or wrong explanation } \\
\text { of touching as the } \\
\text { defining property of } \\
\text { matter }\end{array}$ \\
\hline Examples & $\begin{array}{l}\text { "Matter is everything. Well, } \\
\text { everything I can touch. Even } \\
\text { the air, because, } \\
\text { theoretically, it is touching } \\
\text { me all the time." }\end{array}$ & $\begin{array}{l}\text { "Matter is all the stuff that } \\
\text { is solid and compact." } \\
\text { "Air and water are not } \\
\text { matter because we cannot } \\
\text { grab them." }\end{array}$ & $\begin{array}{l}\text { "I don't know what matter } \\
\text { is." } \\
\text { "If I touch something it } \\
\text { becomes matter." }\end{array}$ \\
\hline
\end{tabular}

Table A2. Coding guide with criteria and examples for key idea number two:

"Reality is described through models. For example the model of particle physics."

\begin{tabular}{|c|c|c|c|}
\hline & Fully adequate & Partially adequate & Not adequate \\
\hline Criteria & $\begin{array}{l}\text { - Explanation of the use of } \\
\text { models in science } \\
\text { - Use of the key word } \\
\text { 'description' } \\
\text { - Mention of the model of } \\
\text { particle physics }\end{array}$ & $\begin{array}{l}\text { - Explanation of the use of } \\
\text { models in science } \\
\text { - Mention of the model of } \\
\text { particle physics } \\
\text { - No or wrong use of the } \\
\text { key word 'description' }\end{array}$ & $\begin{array}{l}\text { - No mention of modelling } \\
\text { - No or wrong explanation } \\
\text { of the use of models }\end{array}$ \\
\hline Examples & $\begin{array}{l}\text { "We have no idea what } \\
\text { reality is, but we have to } \\
\text { describe it somehow. That is } \\
\text { why we need models, for } \\
\text { example the model of } \\
\text { particles in particle physics." }\end{array}$ & $\begin{array}{l}\text { "A model tells us how } \\
\text { reality works." } \\
\text { "In particle physics the } \\
\text { particles are the models we } \\
\text { use." }\end{array}$ & $\begin{array}{l}\text { "I did not understand what } \\
\text { this [modelling] is about." } \\
\text { "I think scientists conduct } \\
\text { experiments, but I do not } \\
\text { know why they need models } \\
\text { for that." }\end{array}$ \\
\hline
\end{tabular}


Table A3. Coding guide with criteria and examples for key idea number three: "In this model, there are atoms, which may combine to form compounds"

\begin{tabular}{|c|c|c|c|}
\hline & Fully adequate & Partially adequate & Not adequate \\
\hline Criteria & $\begin{array}{l}\text { - Mention of atoms } \\
\text { - Explanation that atoms } \\
\text { may combine to form } \\
\text { compounds } \\
\text { - Acknowledgment that } \\
\text { atoms are part of the } \\
\text { model of particle physics }\end{array}$ & $\begin{array}{l}\text { - Mention of atoms } \\
\text { - No or wrong explanation } \\
\text { that atoms may combine } \\
\text { to form compounds }\end{array}$ & $\begin{array}{l}\text { - No mention of atoms } \\
\text { - No or wrong explanation } \\
\text { that atoms may combine } \\
\text { to form compounds }\end{array}$ \\
\hline Examples & $\begin{array}{l}\text { "So, in the model of particle } \\
\text { physics, scientists invented } \\
\text { atoms. Everything is made of } \\
\text { atoms because they can } \\
\text { connect with each other." }\end{array}$ & $\begin{array}{l}\text { "The model of particle } \\
\text { physics uses atoms to } \\
\text { describe what everything is } \\
\text { made of." }\end{array}$ & $\begin{array}{l}\text { "I don't know atoms" } \\
\text { "An atom can swallow other } \\
\text { atoms and then it gets bigger } \\
\text { and bigger. This is how } \\
\text { matter is created." }\end{array}$ \\
\hline
\end{tabular}

Table A4. Coding guide with criteria and examples for key idea number four:

"In this model, atoms are divided into two areas: the nucleus-space and the orbital-space."

\begin{tabular}{|c|c|c|c|}
\hline & Fully adequate & Partially adequate & Not adequate \\
\hline Criteria & $\begin{array}{l}\text { - Mention that atoms are } \\
\text { divided into two areas } \\
\text { - Mention of the nucleus- } \\
\text { space and the orbital- } \\
\text { space } \\
\text { - Acknowledgment that } \\
\text { this division is part of the } \\
\text { model of particle physics }\end{array}$ & $\begin{array}{l}\text { - Mention that atoms are } \\
\text { divided into two areas } \\
\text { - No or wrong mention of } \\
\text { the nucleus-space and } \\
\text { the orbital-space }\end{array}$ & $\begin{array}{l}\text { - Wrong explanation of } \\
\text { the division within the } \\
\text { atomic model } \\
\text { - No or wrong mention of } \\
\text { the nucleus-space and } \\
\text { the orbital-space }\end{array}$ \\
\hline Examples & $\begin{array}{l}\text { "This atom [points to } \\
\text { illustration] can be divided } \\
\text { into the nucleus-space, } \\
\text { which is super, and then } \\
\text { there is the orbital-space } \\
\text { around it, which is super } \\
\text { big. But this is just how we } \\
\text { picture it with the model." }\end{array}$ & $\begin{array}{l}\text { "An atom has some kind of a } \\
\text { substructure. There are these } \\
\text { two areas. But I forgot their } \\
\text { names." }\end{array}$ & $\begin{array}{l}\text { "[hm] I don't really know, } \\
\text { no, I don't think these atoms } \\
\text { can be divided." }\end{array}$ \\
\hline
\end{tabular}


Table A5. Coding guide with criteria and examples for key idea number five: "In the nucleus-space, protons and neutrons are located."

\begin{tabular}{|c|c|c|c|}
\hline & Fully adequate & Partially adequate & Not adequate \\
\hline Criteria & $\begin{array}{l}\text { - Mention of protons and } \\
\text { neutrons } \\
\text { - Explanation of the } \\
\text { nucleus-space as the } \\
\text { location of protons and } \\
\text { neutrons }\end{array}$ & $\begin{array}{l}\text { - Mention of protons and } \\
\text { neutrons } \\
\text { - No or wrong explanation } \\
\text { of the nucleus-space as } \\
\text { the location of protons } \\
\text { and neutrons }\end{array}$ & $\begin{array}{l}\text { - No mention of protons } \\
\text { and neutrons } \\
\text { - No or wrong explanation } \\
\text { of the nucleus-space as } \\
\text { the location of protons } \\
\text { and neutrons }\end{array}$ \\
\hline Examples & $\begin{array}{l}\text { "And as I said, there is the } \\
\text { nucleus-space, which is just } \\
\text { the location in the middle. } \\
\text { This is were we have the } \\
\text { protons and the neutrons." }\end{array}$ & $\begin{array}{l}\text { "In an atom, there are even } \\
\text { smaller things. For example, } \\
\text { these, which are called [ehm] } \\
\text { protons and [ehm] neutrons. } \\
\text { They are somewhere in it." }\end{array}$ & $\begin{array}{l}\text { "I think there was something } \\
\text { special about this nucleus- } \\
\text { orbital, but I can't remember } \\
\text { it anymore." }\end{array}$ \\
\hline
\end{tabular}

Table A6. Coding guide with criteria and examples for key idea number six: "Protons and neutrons are particle systems, which are made of quarks."

\begin{tabular}{|c|c|c|c|}
\hline & Fully adequate & Partially adequate & Not adequate \\
\hline Criteria & $\begin{array}{l}\text { - Use of the key word } \\
\text { 'particle system' } \\
\text { - Mention that protons and } \\
\text { neutrons are particle } \\
\text { systems } \\
\text { - Explanation that particle } \\
\text { systems are made of } \\
\text { quarks }\end{array}$ & $\begin{array}{l}\text { - Use of the key word } \\
\text { 'particle system' } \\
\text { - Mention that protons } \\
\text { and neutrons are particle } \\
\text { systems } \\
\text { - No or wrong explanation } \\
\text { that particle systems are } \\
\text { made of quarks }\end{array}$ & $\begin{array}{l}\text { - No or wrong mention } \\
\text { that protons and } \\
\text { neutrons are particle } \\
\text { systems } \\
\text { - No or wrong explanation } \\
\text { that particle systems are } \\
\text { made of quarks }\end{array}$ \\
\hline Examples & $\begin{array}{l}\text { "Protons, [ehm], and } \\
\text { neutrons also, are not really } \\
\text { particles. They are some kind } \\
\text { of particle system, because } \\
\text { there are these [ehm] quarks, } \\
\text { yes, quarks, and three of } \\
\text { these make one proton or } \\
\text { neutron." }\end{array}$ & $\begin{array}{l}\text { "So, these particles, they are } \\
\text { called proton and neutron. } \\
\text { But they only look like } \\
\text { particles. There are smaller } \\
\text { particles because they } \\
\text { [proton and neutron] are } \\
\text { particle systems. But I forgot } \\
\text { their names. I only know } \\
\text { that it was a funny name." }\end{array}$ & $\begin{array}{l}\text { "In the nucleus-space we } \\
\text { have protons and neutrons. } \\
\text { And they are the smallest } \\
\text { particles that we know of." } \\
\text { "These protons and } \\
\text { neutrons can combine and } \\
\text { then they form particle } \\
\text { systems which are called } \\
\text { [ehm] quark." }\end{array}$ \\
\hline
\end{tabular}


Table A7. Coding guide with criteria and examples for key idea number seven: "Quarks are indivisible. In this model, these are called elementary particles."

\begin{tabular}{|c|c|c|c|}
\hline & Fully adequate & Partially adequate & Not adequate \\
\hline Criteria & $\begin{array}{l}\text { - Mention that quarks are } \\
\text { indivisible } \\
\text { - Use of the key word } \\
\text { 'elementary particle' } \\
\text { - Acknowledgment that } \\
\text { elementary particles are } \\
\text { part of the model of } \\
\text { particle physics }\end{array}$ & $\begin{array}{l}\text { - Mention that quarks are } \\
\text { indivisible } \\
\text { - No or wrong use of the } \\
\text { key word 'elementary } \\
\text { particle' }\end{array}$ & $\begin{array}{l}\text { - No or wrong mention } \\
\text { that quarks are } \\
\text { indivisible } \\
\text { - No or wrong use of the } \\
\text { key word 'elementary } \\
\text { particle' }\end{array}$ \\
\hline Examples & $\begin{array}{l}\text { "Quarks are the smallest } \\
\text { particles that we have found } \\
\text { so far. We think they are } \\
\text { indivisible, but this can } \\
\text { change if we have to change } \\
\text { the model. We call them } \\
\text { elementary particles." }\end{array}$ & $\begin{array}{l}\text { "Quarks are the smallest } \\
\text { particles. And they have a } \\
\text { second special name, but I } \\
\text { think I forgot it. Something } \\
\text { with e [hm]." }\end{array}$ & $\begin{array}{l}\text { "Quarks are made of protons } \\
\text { and sometimes also } \\
\text { neutrons." } \\
\text { "Quarks are also called } \\
\text { electron particles" }\end{array}$ \\
\hline
\end{tabular}

Table A8. Coding guide with criteria and examples for key idea number eight: "In the orbital-space, it is possible to find electrons."

\begin{tabular}{|c|c|c|c|}
\hline & Fully adequate & Partially adequate & Not adequate \\
\hline Criteria & $\begin{array}{l}\text { - Mention of electrons } \\
\text { - Explanation of the } \\
\text { orbital-space as the } \\
\text { location of electrons } \\
\text { - Use of the key phrase 'it } \\
\text { is possible to find' }\end{array}$ & $\begin{array}{l}\text { - Mention of electrons } \\
\text { - No or wrong explanation } \\
\text { of the orbital-space as the } \\
\text { location of electrons } \\
\text { - No or wrong use of the } \\
\text { key phrase 'it is possible } \\
\text { to find' }\end{array}$ & $\begin{array}{l}\text { - No or wrong mention of } \\
\text { electrons } \\
\text { - No or wrong explanation } \\
\text { of the orbital-space as the } \\
\text { location of electrons }\end{array}$ \\
\hline Examples & $\begin{array}{l}\text { "So, and then we have the } \\
\text { big orbital-space around the } \\
\text { nucleus-space. This big area } \\
\text { is made of nothing, it is just } \\
\text { the space where it would be } \\
\text { possible to find electrons. } \\
\text { But we don't know where } \\
\text { exactly they are." }\end{array}$ & $\begin{array}{l}\text { "Aside from protons and } \\
\text { neutrons, well and quarks } \\
\text { also, there are electrons } \\
\text { around." "Electrons are in } \\
\text { the orbital-space." }\end{array}$ & $\begin{array}{l}\text { "Next to the protons, in the } \\
\text { nucleus-space, there are also } \\
\text { electrons." }\end{array}$ \\
\hline
\end{tabular}


Table A9. Coding guide with criteria and examples for key idea number nine: "Electrons are indivisible. In this model, these are called elementary particles."

\begin{tabular}{|c|c|c|c|}
\hline & Fully adequate & Partially adequate & Not adequate \\
\hline Criteria & $\begin{array}{l}\text { - Mention that electrons } \\
\text { are indivisible } \\
\text { - Use of the key word } \\
\text { 'elementary particle' } \\
\text { - Acknowledgment that } \\
\text { elementary particles are } \\
\text { part of the model of } \\
\text { particle physics }\end{array}$ & $\begin{array}{l}\text { - Mention that electrons } \\
\text { are indivisible } \\
\text { - No or wrong use of the } \\
\text { key word 'elementary } \\
\text { particle' }\end{array}$ & $\begin{array}{l}\text { - No or wrong mention } \\
\text { that electrons are } \\
\text { indivisible } \\
\text { - No or wrong use of the } \\
\text { key word 'elementary } \\
\text { particle' }\end{array}$ \\
\hline Examples & $\begin{array}{l}\text { "Electrons are, as far as we } \\
\text { know, indivisible. Same as } \\
\text { the quarks. That's why, for } \\
\text { now, we call them } \\
\text { elementary as well. But this } \\
\text { is just a model." }\end{array}$ & $\begin{array}{l}\text { "Electrons are indivisible, } \\
\text { we can't split them } \\
\text { anymore." }\end{array}$ & $\begin{array}{l}\text { "These electron particles are } \\
\text { elementary, which means we } \\
\text { can divide them further." }\end{array}$ \\
\hline
\end{tabular}

Table A10. Coding guide with criteria and examples for key idea number ten:

"In this model, apart from particles, there is only empty space."

\begin{tabular}{|c|c|c|c|}
\hline & Fully adequate & Partially adequate & Not adequate \\
\hline Criteria & $\begin{array}{l}\text { - Mention of empty space } \\
\text { - Distinction between } \\
\text { particles and empty } \\
\text { space } \\
\text { - Acknowledgment that } \\
\text { particles and empty } \\
\text { space are part of the } \\
\text { model of particle physics }\end{array}$ & $\begin{array}{l}\text { - Mention of empty space } \\
\text { - No or wrong distinction } \\
\text { between particles and } \\
\text { empty space }\end{array}$ & $\begin{array}{l}\text { - No mention of empty } \\
\text { space } \\
\text { - No or wrong distinction } \\
\text { between particles and } \\
\text { empty space } \\
\text { - Comparison of empty } \\
\text { space with air }\end{array}$ \\
\hline Examples & $\begin{array}{l}\text { "There are only some } \\
\text { particles, which are very } \\
\text { small. Everything else is } \\
\text { empty. Apart from particles, } \\
\text { there is nothing else." }\end{array}$ & $\begin{array}{l}\text { "In the orbital-space, [ehm] } \\
\text { and in the nucleus-space, } \\
\text { there is nothing." }\end{array}$ & $\begin{array}{l}\text { "An atom is essentially } \\
\text { empty. There is nothing we } \\
\text { can touch, only air." }\end{array}$ \\
\hline
\end{tabular}


Checklist of the research manual for teachers

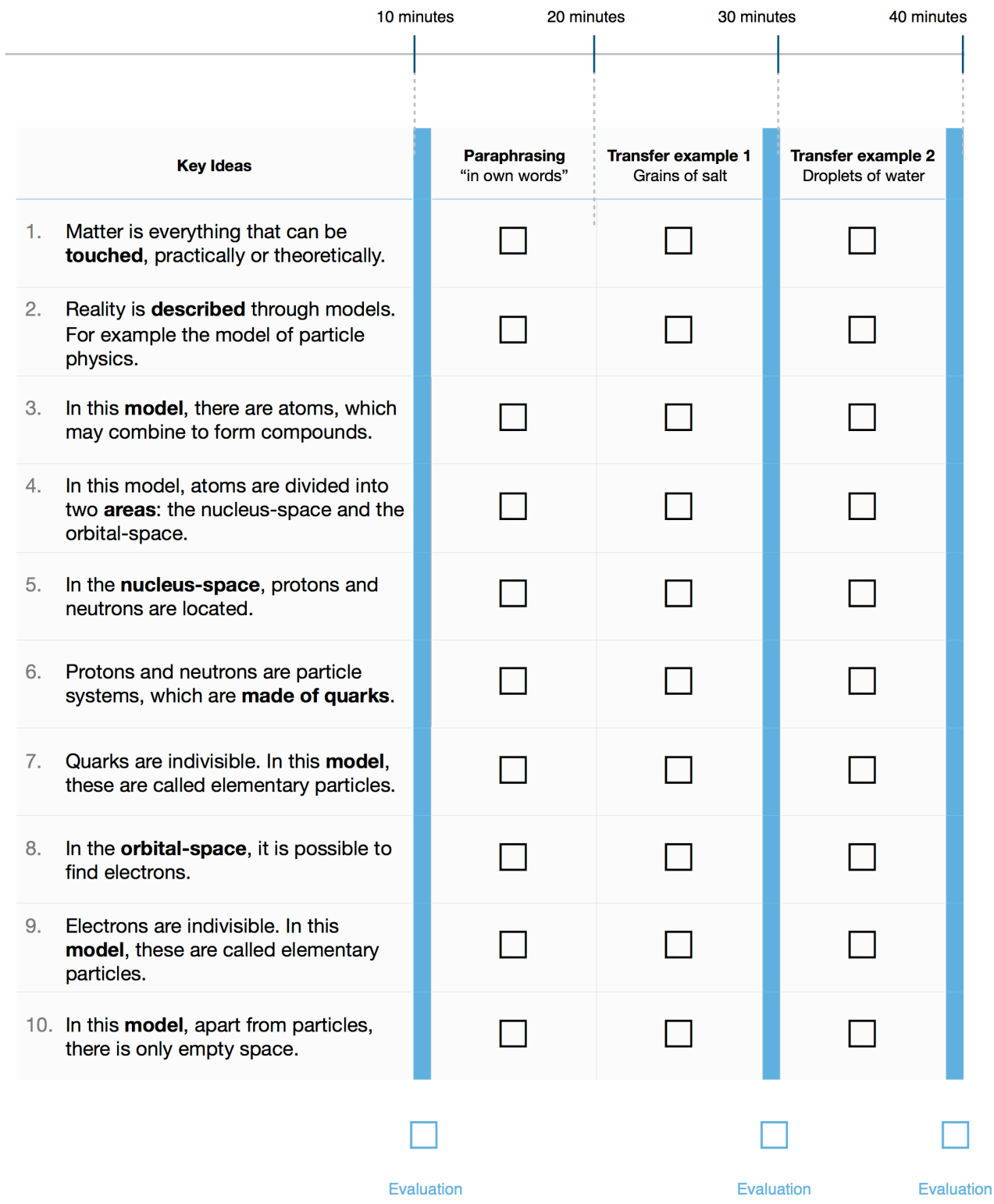

